\title{
TET3 overexpression facilitates DNA reprogramming and early development of bovine SCNT embryos
}

\author{
Jian Zhang1,2,*, Linlin $\mathrm{HaO}^{3, *}$, Qian Wei ${ }^{4}$, Sheng Zhang ${ }^{5}$, Hui Cheng ${ }^{1}$, Yanhui Zhai ${ }^{1}$, Yu Jiang ${ }^{1}$, \\ Xinglan An ${ }^{5}$, Ziyi $\mathrm{Li}^{5}$, Xueming Zhang ${ }^{1}$ and Bo Tang ${ }^{1}$ \\ ${ }^{1}$ College of Veterinary Medicine, Jilin University, Changchun, Jilin, China, ${ }^{2}$ Department of Biology, Southern \\ University of Science and Technology, Shenzhen, Guangdong, China, ${ }^{3}$ Department of Radiotherapy, Second \\ Hospital, Jilin University, Changchun, Jilin, China, ${ }^{4}$ Department of Heat Disease, Affiliated Hospital to Changchun \\ University of Chinese Medicine, Changchun, Jilin, China and ${ }^{5}$ Academy of Translational Medicine, First Hospital, \\ Jilin University, Changchun, Jilin, China
}

Correspondence should be addressed to X Zhang or B Tang; Email: zhangxuem@jlu.edu.cn or tang_bo@jlu.edu.cn

*(J Zhang and L Hao contributed equally to this work)

\begin{abstract}
Somatic cell nuclear transfer (SCNT) has been successfully used for cloning in a variety of mammalian species. However, SCNT reprogramming efficiency is relatively low, in part, due to incomplete DNA methylation reprogramming of donor cell nuclei. We previously showed that ten-eleven translocation 3 (TET3) is responsible for active DNA demethylation during preimplantation embryonic development in bovines. In this study, we constructed TET3-overexpressing cell lines in vitro and observed that the use of these fibroblasts as donor cells increased the blastocyst rate by approximately 18 percentage points compared to SCNT. The overexpression of TET3 in bovine SCNT embryos caused a decrease in the global DNA methylation level of the pluripotency genes Nanog and Oct-4, ultimately resulting in an increase in the transcriptional activity of these pluripotency genes. Moreover, the quality of bovine TET3-NT embryos at the blastocyst stage was significantly improved, and bovine TET3-NT blastocysts possessed more total number of cells and fewer apoptotic cells than the SCNT blastocysts, similar to in vitro fertilization (IVF) embryos. Nevertheless, DNA methylation of the imprinting control region (ICR) for the imprinted genes H19-IGF2 in SCNT embryos remained unaffected by TET3 overexpression, maintaining parent-specific activity for further development. Thus, the results of our study provide a promising approach to rectify incomplete epigenetic reprogramming and achieve higher cloning efficiency.

Reproduction (2020) 160 379-391
\end{abstract}

\section{Introduction}

Somatic cell nuclear transfer (SCNT) is a powerful tool by which the differentiated somatic cell genome can be reprogrammed back into a totipotent state through a reprogramming mechanism (Gurdon 1962, Wilmut et al. 1997). Animal production using SCNT has great potential for the development of therapeutic and regenerative medicine as well as in agriculture and species preservation (Andrabi \& Maxwell 2007, Yang et al. 2007). However, the efficiency of SCNT for most mammalian species is extremely low. Aberrant reprogramming of the somatic donor nucleus is one of the major causes of the decreased probability of obtaining cloned embryos, which limits the application of SCNT technology in many areas (Dean et al. 2001, Armstrong et al. 2006).

Various epigenetic abnormalities in SCNT embryos have been identified and often lead to developmental arrest through mechanisms such as DNA methylation, histone modifications, and genomic imprinting, which are thought to determine activation of the embryonic genome (Dean et al. 2001, Wang et al. 2007, Okae et al. 2014). Therefore, a series of approaches to improve epigenetic reprogramming, such as decreasing DNA methylation levels in the reconstructed embryos by DNA methyltransferase inhibitors, increasing histone acetylation levels by histone deacetylase inhibitors, and reducing histone methylation levels in SCNT embryos by demethylase overexpression, have been reported (Enright et al. 2005, Van Thuan et al. 2009, Hormanseder et al. 2017). These studies offer several effective approaches to improve the efficiency of SCNT embryos to a certain extent.

In mice, the dioxygenase ten-eleven translocation 3 (TET3) acts to demethylate the parental genome by converting 5-methylcytosine $(5 \mathrm{mC})$ into 5-hydroxymethylcytosine (5hmC), 5-formylcytosine (5fC) and 5-carboxycytosine (5caC) (Gu et al. 2011, 
He et al. 2011). By performing inhibition and knockdown experiments on IVF and parthenogenetically activated (PA) embryos, the results of our recent study confirmed that TET3 is responsible for active DNA demethylation during bovine embryonic development (Zhang et al. 2017, Cheng et al. 2019). Previous studies have shown that there is an inverse correlation between abnormal DNA methylation and SCNT efficiency (Wei et al. 2011). DNA methylation levels have been observed to be abnormally high in SCNT embryos of different species, and aberrant DNA methylation profiles can be identified even after implantation (Peat \& Reik 2012, Zhang et al. 2016). Therefore, proper DNA methylation reprogramming from the donor cell to the zygote is essential for successful SCNT.

In the present study, we used sodium bisulfite genomic sequencing (BSP) technology to detect and validate the level of DNA methylation in bovine SCNT embryos. We observed aberrantly increased levels of DNA methylation in SCNT embryos compared to IVF embryos. We subsequently produced bovine SCNT embryos using TET3-overexpressed fibroblasts with the SCNT technique. The cloned embryos exhibited significantly enhanced transcriptional reprogramming and improved developmental potential. Thus, our results identified a crucial factor associated with unsuccessful nuclear reprogramming and provide a more accurate method to improve the efficiency of bovine SCNT embryos.

\section{Materials and methods}

All chemicals and reagents were purchased from SigmaAldrich, unless otherwise specified.

\section{Ethics statement}

Bovine ovaries from slaughtered mature cattle were collected from a local abattoir in Changchun, China. Frozen-thawed bovine semen was purchased from Ketian Co., Ltd. (Changchun, China). All experimental materials and procedures were approved by the Animal Welfare and Research Ethics Committee at Jilin University (approval ID: 20151008-1).

\section{Cell culture and transfection}

Bovine embryo fibroblasts (BEFs) were isolated and cultured from Yanbian yellow cattle fetuses as previously described (Wang et al. 2011). Commercially synthesized full-length TET3 cDNA was inserted into the vector pHBLV (Hanbio Biotechnology, Shanghai, China), which was then packaged by three-way transfection of HEK-293T cells using the packaging plasmids pSPAX2 and pMD2G.

At $48 \mathrm{~h}$ after transfection, the viral supernatant was harvested, ultracentrifuged to remove floating 293T cells, and frozen at $-80^{\circ} \mathrm{C}$ until used to infect target cells. Then,
BEFs at passage 2-4 were seeded in 6-well plates, cultured to $70 \%$ confluency and infected with a mixture of virus at an multiplicity of infection (MOI) of 40 in a solution containing 8 $\mu \mathrm{g} / \mathrm{mL}$ polybrene. After incubating for $24 \mathrm{~h}$, the viral solution was replaced with fresh complete medium and incubated for another $24 \mathrm{~h}$. Positive transgenic clones were identified with a fluorescence microscope (Nikon) and selected for by the addition of $2 \mu \mathrm{g} / \mathrm{mL}$ puromycin to the culture medium every 2-3 days. After the nontransfected cells were killed, positive transgenic cells were cultured in fresh medium and used for further experiments.

\section{Oocyte collection and in vitro maturation}

Bovine ovaries were obtained from a local abattoir (Changchun, China) and transported into the lab in sterile saline within 2-3 h. Cumulus oocyte complexes (COCs) were aspirated from 3-8 $\mathrm{mm}$ bovine ovarian follicles using a $10-\mathrm{mL}$ disposable syringe with a 12-gauge needle. COCs with compact cumulus cells were cultured in vitro in maturation medium (TCM-199 medium supplemented with sodium bicarbonate, $10 \%$ fetal bovine serum, $1 \mu \mathrm{g} / \mathrm{mL}$ follicle-stimulating hormone and 10 $\mu \mathrm{g} / \mathrm{mL}$ luteinizing hormone) in a humidified incubator under an atmosphere with $5 \% \mathrm{CO} 2$ at $38.5^{\circ} \mathrm{C}$ for $20-22 \mathrm{~h}$ for IVF or 16-18 h for SCNT.

\section{In vitro fertilization (IVF) and embryo culture}

Fresh semen was washed two times with $5 \mathrm{~mL}$ of Dulbecco's PBS and then centrifuged at $250 \mathrm{~g}$ for $5 \mathrm{~min}$. The spermatozoa concentration was adjusted to $1 \times 10^{6}$ sperm $/ \mathrm{mL}$ using a hemocytometer, and the swim-up sperm were then collected to prepare fertilization droplets $(100 \mu \mathrm{L})$. Mature oocytes were washed two times in TALP medium. Approximately 20-25 oocytes were transferred into $100-\mu \mathrm{L}$ droplets and incubated with capacitation of sperm for $20 \mathrm{~h}$ at $38.5^{\circ} \mathrm{C}$ under an atmosphere with 5\% CO2 in air. After fertilization, presumptive zygotes were removed from excessive sperm and cultured in synthetic oviduct fluid (Sofaa) containing 10\% fetal bovine serum (FBS) at $38.5^{\circ} \mathrm{C}$ under an atmosphere with $5 \%$ CO2 and $95 \%$ humidity.

\section{Somatic cell nuclear transfer (SCNT) and embryo culture}

Donor cells for SCNT were derived from BEFs at passages 3-6 and cultured in serum-free DMEM (Gibco) with 1\% FBS (Gibco) for $24 \mathrm{~h}$ at $37^{\circ} \mathrm{C}$ under an atmosphere with 5\% CO2 in air to synchronize cells at G0/G1 phase of the cell cycle. The SCNT process was performed as previously described (Stelzer et al. 2016). Briefly, mature and enucleated oocytes with the first polar body were placed in TCM-199 medium-HEPES containing $7.5 \mu \mathrm{g} / \mathrm{mL}$ cytochalasin B. After enucleation using a beveled glass pipette, a single donor cell was individually transferred to the perivitelline space of each oocyte. Then, the couplets were fused in mannitol fusion buffer with one direct pulse of $1.8 \mathrm{kV} / \mathrm{cm}$ for $10 \mu \mathrm{s}$ by an Electro Cell Manipulator 2001 (BTX, San Diego, CA, USA). All the reconstructed 
embryos were activated with $5 \mu \mathrm{M}$ ionomycin for $5 \mathrm{~min}$, followed by $4 \mathrm{~h}$ of exposure to $2 \mathrm{mM}$ 6-dimethylpyridine in SOF medium containing $10 \%$ FBS at $38.5^{\circ} \mathrm{C}$ under an atmosphere with 5\% CO2 and 95\% humidified air. Then, the activated SCNT embryos were cultured as described for IVF (Zhang et al. 2017).

\section{Immunofluorescence staining}

The zona pellucida (ZP) of bovine embryos was dissolved by treatment with $0.5 \%$ Pronase and fixed with $4 \%$ paraformaldehyde for $30 \mathrm{~min}$ at room temperature. After three washes with PBS-PVA, embryos and cells were permeabilized with $0.1 \%$ Triton X-100 prepared in PBS-PVA for $20 \mathrm{~min}$ and then blocked for $1 \mathrm{~h}$ at room temperature in PBS-PVA containing $2 \%$ BSA. Following incubation overnight at $4^{\circ} \mathrm{C}$ with primary antibodies targeting FLAG (diluted 1:100; Beyotime; Shanghai, China), TET3 (diluted 1:50; Santa, CA, USA), 5mC (diluted 1:200; Eurogentec, Liege, Belgium) and 5hmC (diluted 1:200; Active Motif, Carlsbad, CA, USA), embryos and cells were washed with PBS-PVA and stained at $37^{\circ} \mathrm{C}$ for $1.5 \mathrm{~h}$ with Alexa Fluor 488 (1:200; Invitrogen) and Alexa Fluor 594 (1:200; Invitrogen). For $5 \mathrm{mC} / 5 \mathrm{hmC}$ staining, two additional treatments were performed before blocking: embryos and cells were incubated with $4 \mathrm{~N} \mathrm{HCl}$ for $30 \mathrm{~min}$ and then Tris- $\mathrm{HCl}$ buffer $(100 \mathrm{mM}, \mathrm{pH}$ 8.5) for $20 \mathrm{~min}$. DNA was stained with $10 \mu \mathrm{g} / \mathrm{mL}$ DAPI for $10 \mathrm{~min}$. All samples were immediately mounted and observed under a fluorescence microscope (Nikon), and images of embryos and cells were taken using the same microscope setting and exposure times. The average fluorescence intensity of embryos was evaluated using ImageJ (National Institutes of Health, Bethesda, MD) based on procedures described elsewhere (Aflalo et al. 2005). The data shown are representative of at least three independent experiments.

\section{Western blot analysis}

Cells were collected and lysed with RIPA buffer, and protein concentration was measured using a BCA protein assay kit (Thermo Scientific). The proteins were separated via SDSPAGE and then transferred to PVDF membranes, which were subsequently blocked in 5\% BSA and incubated with primary antibodies targeting FLAG (diluted 1:200; Beyotime; Shanghai, China) and Gapdh (diluted 1:500; BOSTER; CA, USA) overnight. The membranes were washed three times in TBST and then incubated for $1 \mathrm{~h}$ with HRP anti-rabbit (diluted 1:2000; BOSTER) and HRP anti-mouse (1:2000; BOSTER) antibodies. Then, the membranes were washed three times in TBST and visualized using ECL Detection Reagents (Pierce;
Thermo Scientific). Images were obtained using an LAS-4000 Imager (Fuji).

\section{RNA isolation and RT-qPCR}

Total RNA was extracted from BEFs using TRIzol reagent and from embryos at different stages using an RNeasy Mini Kit (Qiagen) according to the manufacturer's protocol. First-strand cDNA was synthesized using a cDNA synthesis kit (Promega). Real-time PCR was performed in 96-well optical reaction plates using SYBR ${ }^{\circledR}$ Premix Ex TaqTM reagents (TaKaRa) and the primers listed in Supplementary Table 1 (see section on supplementary materials given at the end of this article) in a LightCycler 96 Real-Time PCR System (Roche). Each 20- $\mu \mathrm{L}$ PCR mixture contained $2 \mu \mathrm{L}$ of cDNA, $10 \mu \mathrm{L}$ of SYBR Green premix, $6 \mu \mathrm{L}$ of RNase-free water, and $1 \mu \mathrm{L}$ each of the forward and reverse primers for each gene. The following program was used to amplify all genes: denaturation at $95^{\circ} \mathrm{C}$ for $60 \mathrm{~s}, 42$ cycles of PCR for quantitative analysis $\left(95^{\circ} \mathrm{C}\right.$ for $5 \mathrm{~s}$ and $60^{\circ} \mathrm{C}$ for $30 \mathrm{~s})$, melt curve analysis $\left(95^{\circ} \mathrm{C}\right.$ for $5 \mathrm{~s}, 60^{\circ} \mathrm{C}$ for $60 \mathrm{~s}$, and $95^{\circ} \mathrm{C}$ for $1 \mathrm{~s}$ ), and cooling at $4^{\circ} \mathrm{C}$. Relative gene expression data were analyzed using the $2^{-\Delta \Delta C T}$ method (Livak \& Schmittgen 2001). Quantitative PCR analysis was performed three times per sample. Values were normalized to bovine GAPDH mRNA expression.

\section{Sodium bisulfite genomic sequencing}

Bisulfite sequencing was used to measure the locus-specific DNA methylation status of BEFs, oocytes, and IVF and SCNT blastocysts as previously described (Zhang et al. 2016). In short, genomic DNA was subjected to bisulfite transformation, and PCR was performed using the primers shown in Table 1. PCR products were gel recovered using an Axy Prep DNA Gel Extraction kit (Axygen, Beijing, China) and then cloned into the vector PmdTM18-T (TaKaRa). The recombinant plasmid was transformed into $\mathrm{DH} 5 \alpha$ competent cells (TaKaRa), and at least 30 positive clones were selected for sequencing. BiQ analysis software was used to evaluate the DNA methylation level as the ratio of the methylated CpG number to the total CpG number (Bock et al. 2005).

\section{TUNEL assay}

To determine the number of apoptotic cells in blastocysts, the DeadEnd Fluorometric TUNEL System (Roche) was used as previously described (Lu et al. 2014). Samples were observed with a fluorescence microscope (Nikon) with the same exposure time and image capture settings to enable relative

Table 1 Effect of TET3 overexpression on bovine SCNT embryonic development in vivo.

\begin{tabular}{lccc}
\hline Group & No. of embryos examined & No. of 2-cell cleavage $(\%)$ & No. of 8-cell cleavage $(\%)$ \\
\hline IVF & 233224 & $204(87.8 \pm 1.8)^{\mathrm{a}}$ & $145(62.3 \pm \pm 4.1)^{\mathrm{a}}$ \\
SCNT & $130(61.2 \pm 3.6)^{\mathrm{b}}$ & $66(31.1 \pm 2.9)^{\mathrm{b}}$ & $78(33.8 \pm 1.7)^{\mathrm{a}}$ \\
TET3-NT & $188(84.3 \pm 4.1)^{\mathrm{a}}$ & $25(12.1 \pm 0.9)^{\mathrm{b}}$ & $124(55.7 \pm 2.4)^{\mathrm{a}}$ \\
\hline
\end{tabular}

Data are the mean \pm S.E.M. of at least three trials.

${ }^{a, b}$ Different superscript letters within the same column express significant differences $(P<0.05)$. 
comparisons. Each experiment was carried in at least three biological replicates.

\section{Statistical analysis}

Data that were derived from at least three independent experiments and analyzed using two-tailed Student's t-test with SPSS Statistics 19.0 (IBM Corporation) are presented as the mean \pm S.E.M. Values of $P<0.05$ indicated significance; values of $P<0.01$ indicated extreme significance.

\section{Results}

\section{Successful expression of exogenous TET3 in BEF}

In this study, we obtained the TET3 CDS of bovine endogenous TET3 and used it to overexpress TET3 in bovine fibroblasts. To obtain TET3-transfected cells, the overexpression vector pHBLV-CMV-TET3-3FLAG -EF1-ZsGreen-T2A-Puro was successfully constructed according to the schematic diagram of the vector (Fig. 1A), and the TET3 gene was expressed with the CMV promoter. After lentiviral transfection and selection with puromycin, the expression of TET3 was validated through immunohistochemical staining (Fig. 1B). Realtime PCR was used to assess the expression of TET3 in bovine fetal fibroblasts at $48 \mathrm{~h}$ after transfection, and the results demonstrated that TET3 transcription was significantly increased (by 75-fold) at $72 \mathrm{~h}$ after TET3 transfection compared to that observed in the Blank group (WT) and the N.C. group (BEFs transfected with an empty vector that did not contain TET3) (Fig. 1C). Immunofluorescence results also showed that the TET3 protein was highly expressed in BEFs stably transfected with TET3 (E.G.) (Fig. 1D). In addition, the immunofluorescence and Western blot results showed that the FLAG-TET3 fusion protein was detected in only the nuclei of BEFs transfected with the TET3 construct (Fig. 1E and F).

\section{Activation of pluripotency genes in BEFs by TET3 overexpression}

To determine whether ectopic TET3 expression affects other genes associated with epigenetic and pluripotency related genes in fibroblasts prior to nuclear transfer, the expression levels of related genes were assessed by realtime PCR. The results showed that the mRNA expression levels of the pluripotency genes Nanog, Sox2, and Oct-4 were significantly increased in the TET3 overexpression group compared to those observed in the Blank and N.C. groups, while $C d \times 2$ expression was not detected in any of the three groups (Fig. 2A). In addition, the mRNA levels of genes encoding DNA methyltransferases (DNMT3a and DNMT3b), lysine-specific demethylases (KDM3A, KDM4A, KDM4C, and KDM5B) and imprinted genes (H19 and Igf2) were not significantly different

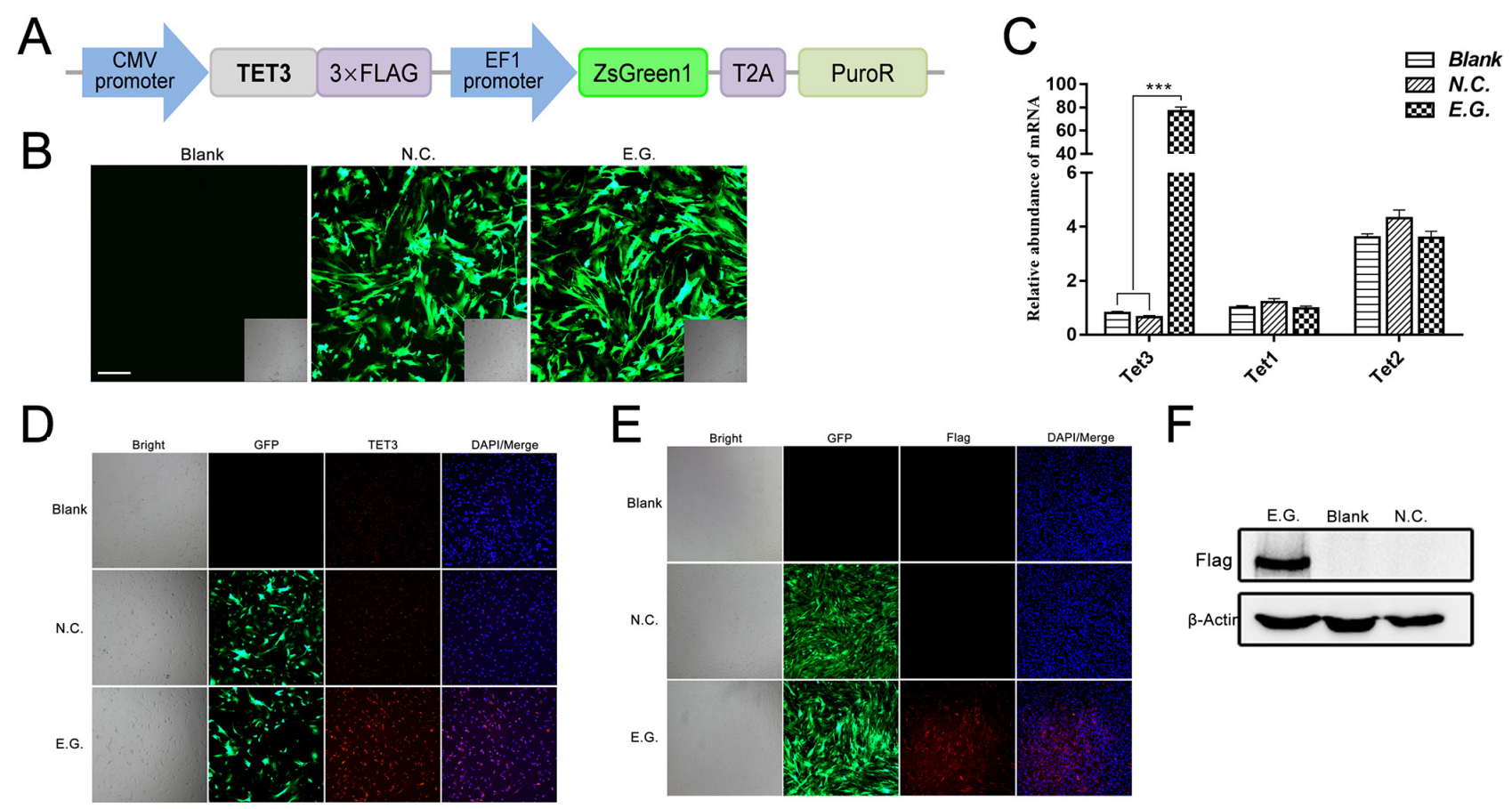

Figure 1 Successful expression of the TET3 protein in BEFs. (A) Schematic diagram of the overexpression vector pHBLV-CMV-TET3-3FLAG -EF1-ZsGreen-T2A-Puro. (B) Representative green fluorescence image of a BEF transfected with TET3. (C) Real-time PCR results assessing the expression of Tet family in BEFs $72 \mathrm{~h}$ after transfection with TET3. (D) Morphology and TET3 expression of Blank, N.C. and E.G. BEFs. (E and F) FLAG-TET3 fusion protein was detected in the nuclei of transfected BEFs by immunofluorescence and Western blot analyses. The data are presented as the mean \pm S.E.M. ${ }^{* * *} P<0.001$. Scale bar $=100 \mu \mathrm{m}$. 

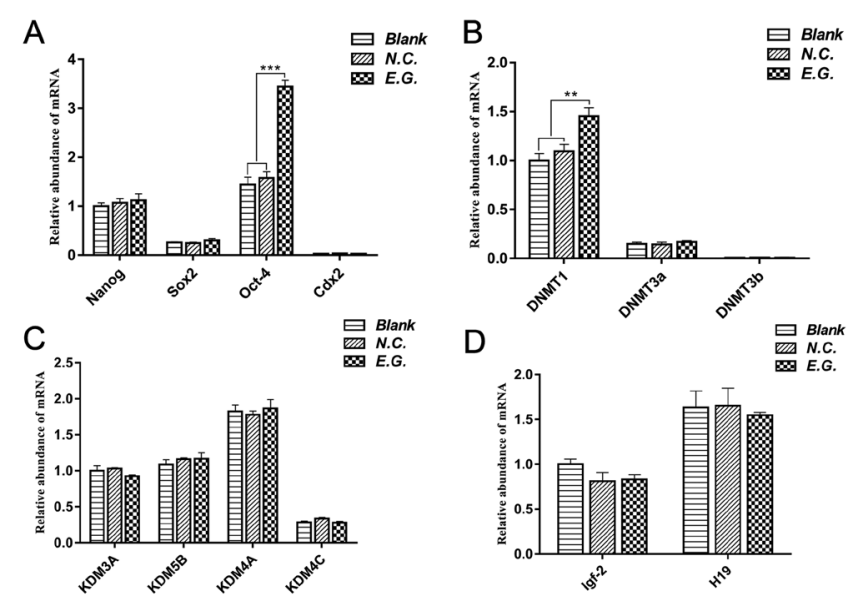

Figure 2 Relative mRNA abundances of various genes. (A, B, C and D) Expression of DNA methyltransferase (DNMT), lysine-specific demethylase (KDM) and imprinted genes in the Blank, N.C. and E.G. bovine fibroblasts. GAPDH was used as an internal control. The gene expression levels in the Blank were used to calibrate the sample (expression set to 1 ). The data are presented as the mean \pm S.E.M. **P $<0.01,{ }^{* * *} P<0.001$.

among the three cell lines; however, the expression of the DNA methyltransferase-encoding gene DNMT1 was upregulated in the E.G. group compared to that observed in the Blank and N.C. groups (Fig. 2B, C and D).

\section{Overexpression of TET3 improves bovine SCNT embryonic development}

Having established that TET3 was enriched in BEFs, we asked whether TET3 overexpression would aid in overcoming the DNA methylation reprogramming barrier in bovine SCNT embryos. To this end, we performed SCNT using TET3-overexpressing BEFs as nuclear donors, and the GFP protein levels at the reconstructed embryo, 2-cell embryo, 4-cell embryo, 8-cell embryo and blastocyst stages were examined via fluorescence microscopy (Fig. 3A). In addition, WT bovine SCNT embryos and IVF embryos were used as controls. The effects on embryonic development are shown in Table 1. Cleavage rates and 8-cell and blastocyst formation rates in the TET-NT embryos were significantly higher than those observed in the WT SCNT embryos but still much lower than those detected in the IVF embryos (Fig. 3B). As expected, the TET3 protein was more highly expressed in the TET3-NT embryos than in the WT SCNT embryos and IVF embryos, with little expression detected in the WT SCNT embryos (Fig. 3C and E). Immunostaining results revealed that TET3 overexpression greatly reduced $5 \mathrm{mC}$ levels in the nuclei of bovine SCNT embryos, which showed the same methylation pattern as the IVF embryos (Fig. 3D and $F$ ). The results indicated that the reprogramming barrier of DNA methylation in the somatic genome can be eliminated by TET3 demethylases in bovine SCNT embryos.

\section{Dynamic DNA methylation patterns of satellite I and $\alpha$-satellite during the early development of bovine embryos}

To further evaluate the global trend in DNA methylation, we also assessed the DNA methylation status of repeat elements ( $\alpha$-satellite and satellite I) using sodium bisulfite genomic sequencing in bovine embryos. The results showed high satellite I and $\alpha$-satellite DNA methylation levels in bovine oocytes (63.2\% vs $55.9 \%$, respectively) and BEFs ( $85.1 \%$ vs $83.4 \%$, respectively), and the DNA methylation of both repeat elements in bovine IVF embryos decreased steadily in 8 -cell embryos (23.9\% vs $37.5 \%$, respectively) and blastocysts $(19.4 \%$ vs $25.6 \%$, respectively) (Fig. $4 \mathrm{~A}$ and $\mathrm{C}$ ), indicating that the DNA demethylation process took place during IVF. Unlike the IVF group, among WT SCNT embryos, satellite I and $\alpha$-satellite DNA methylation remained high in 8-cell embryos (78.9\% vs $72.0 \%$, respectively) and blastocysts (76.6\% vs $70.9 \%$, respectively) (Fig. $4 \mathrm{~A}$ and C). Subsequently, we tested DNA methylation levels in the TET-NT group and observed that satellite I and $\alpha$-satellite methylation profiles were similar to those of IVF embryos at the 8-cell and blastocyst stages (Fig. 4B and D), which was consistent with the $5 \mathrm{mC}$ staining results (Fig. 3D). These results suggest that the reprogramming barrier, DNA methylation in the somatic cell genome, could be eliminated by overexpression of TET3 demethylases in bovine SCNT embryos.

\section{TET3 overexpression restores pluripotent gene transcriptome in bovine SCNT embryos}

To better elucidate the mechanism associated with the improved development of TET3-overexpressing SCNT embryos, we focused on pluripotency-related genes and the methylation status of their promoters. We first detected TET3 expression in the TET3-NT group, which was significantly upregulated compared to that observed in the WT SCNT and IVF embryos at the 8-cell and blastocyst stages (Fig. 5A). Furthermore, the expression of Nanog, Oct-4 and Sox2, three transcription factors that are essential for maintaining pluripotency, were analyzed in these three groups, and the results showed that TET3 overexpression in transgenic NT embryos could activate the endogenous expression of these transcription factors, as their levels were much higher than those observed in the WT SCNT embryos at the 8-cell and blastocyst stages (Fig. 5B, C and F). However, we observed no significant difference in $C d x 2$ mRNA levels between the three groups (Fig. 5D).

DNA methylation, which has been identified as a concomitant abnormal modification in bovine cloned embryos, is known to affect gene expression (Santos et al. 2003). Therefore, we used BSP to test DNA methylation levels at the Nanog and Oct-4 gene promoter regions in IVF and SCNT embryos at the 8-cell and blastocyst 
A
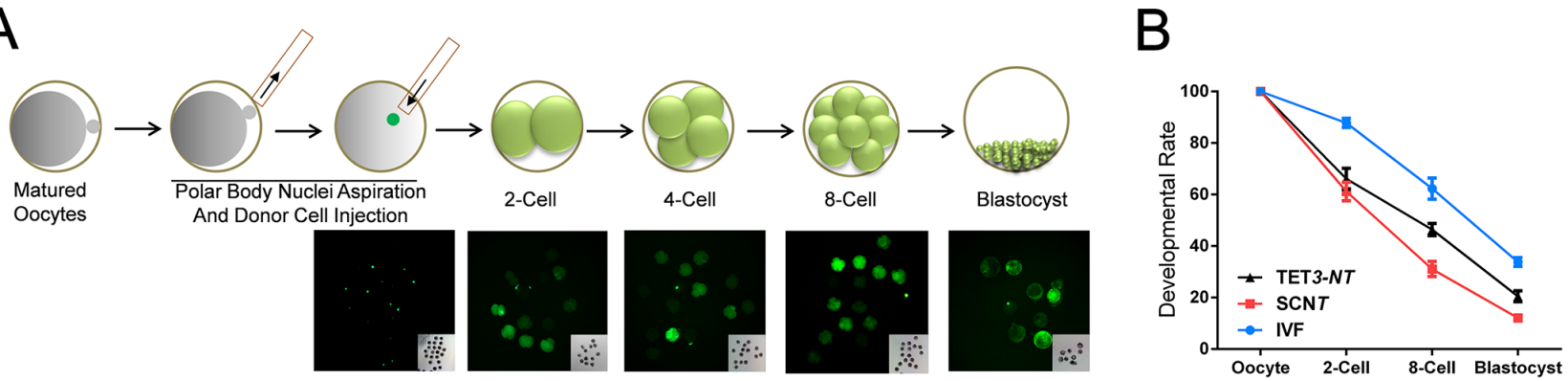
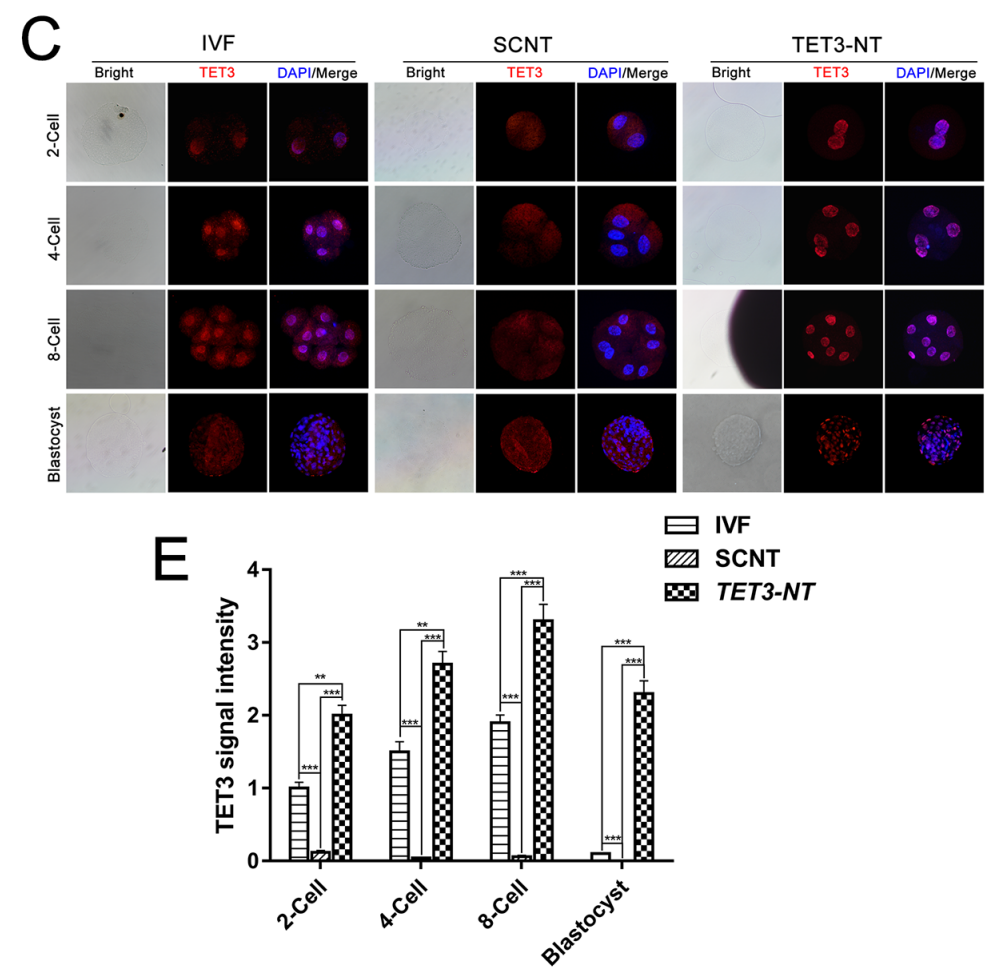

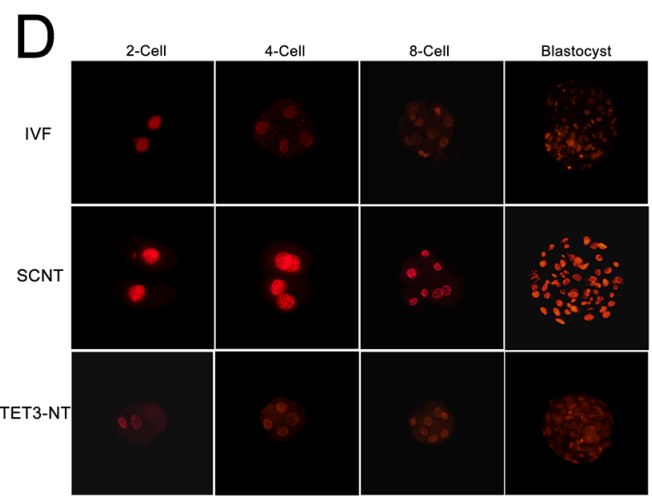

曰IVF
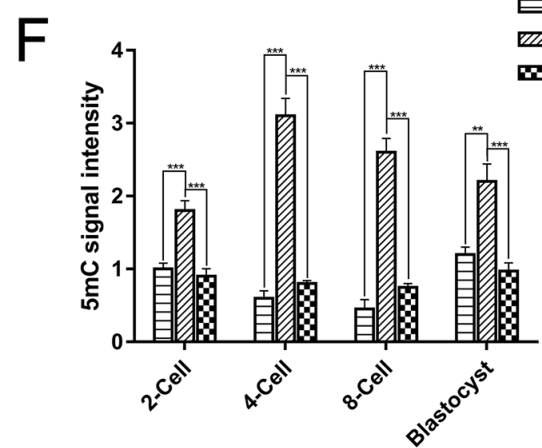

Figure 3 Overexpression of TET3 improves the development of bovine SCNT embryos by removing aberrant DNA methylation. (A) Schematic illustration of the bovine SCNT procedures. (B) Preimplantation development rates in the IVF, SCNT and TET3-SCNT groups. Error bars represent the s.E.M. of five biological replicates. (C) TET3 (red) and DAPI staining (blue) in two-cell to blastocyst IVF, SCNT and TET3-NT embryos. Each sample was counter-stained with DAPI to visualize DNA. (D) Methylation patterns were determined based on the relative levels of 5-methylcytosine $(5 \mathrm{mC})$ in two-cell to blastocyst IVF, SCNT and TET3-NT embryos. (E and F) Average optical intensity of global TET3 and DNA methylation measured using Image J. The data are presented as the means \pm S.E.M. $(P<0.05)$. Scale bars $=300 \mu \mathrm{m}(\mathrm{A}), 50 \mu \mathrm{m}(\mathrm{C}$ and D).

stages, BEFs, and bovine oocytes. The results showed that the methylation levels of the Nanog and Oct-4 promoter regions in IVF embryos were lower than those observed in oocytes and BEFs. In addition, Nanog and Oct-4 were more highly methylated in WT SCNT embryos than that observed in IVF embryos and the methylation profiles of Nanog and Oct- 4 in SCNT embryos were similar to those observed in donor cells (Fig. 6A and C). These results suggest that incomplete removal of DNA methylation can result in inconsistent activation of pluripotency genes. Furthermore, the methylation profiles in TET3-NT embryos were observed to be similar to those observed in IVF embryos but were much different from those observed in WT SCNT embryos, suggesting that TET3 overexpression can restore the global transcriptional status in clone embryos.

\section{Gene expression and DNA methylation of imprinting genes}

Abnormal imprinting patterns observed in cloning often lead to maladjustment of parental gene expression. Bisulfite sequencing and real-time PCR were used to determine the methylation status and expression of the H19/IGF2 ICR (Fig. 7). The results showed that the ICR was highly methylated in BEFs (81.8\%). Moderate DNA methylation of the ICR was maintained in bovine IVF embryos at the 8 -cell $(46.2 \%)$ and blastocyst 
A

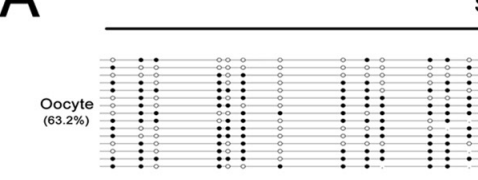

Satellite I

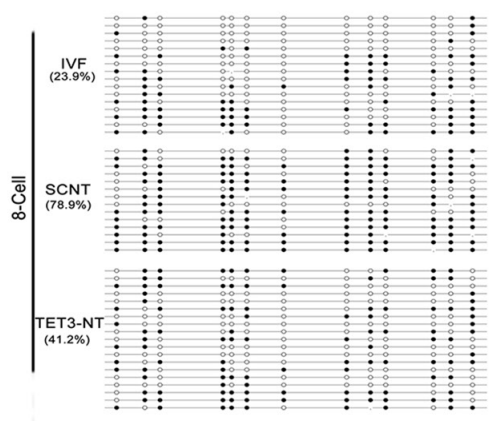

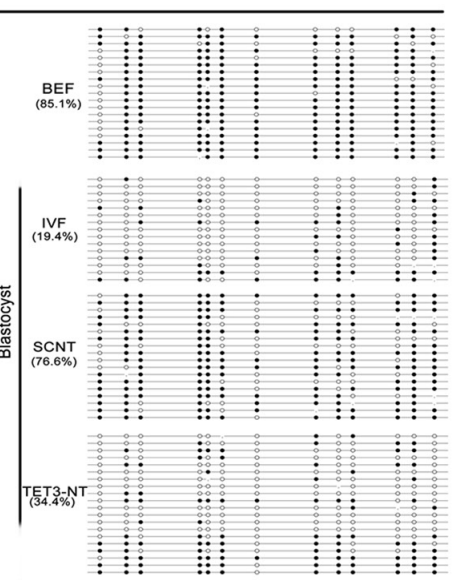

B

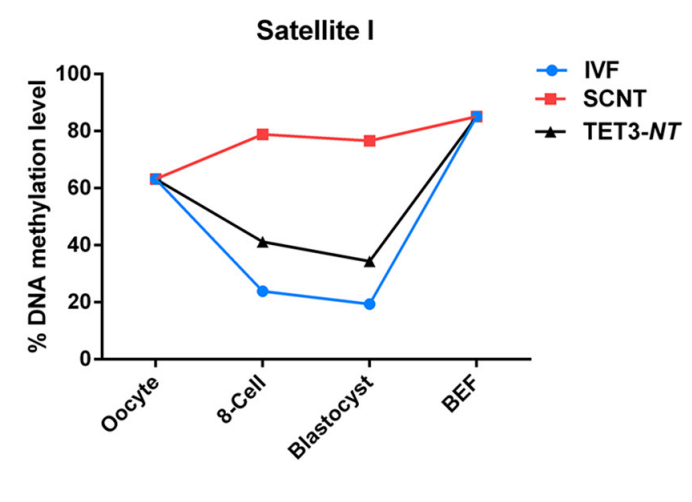

D

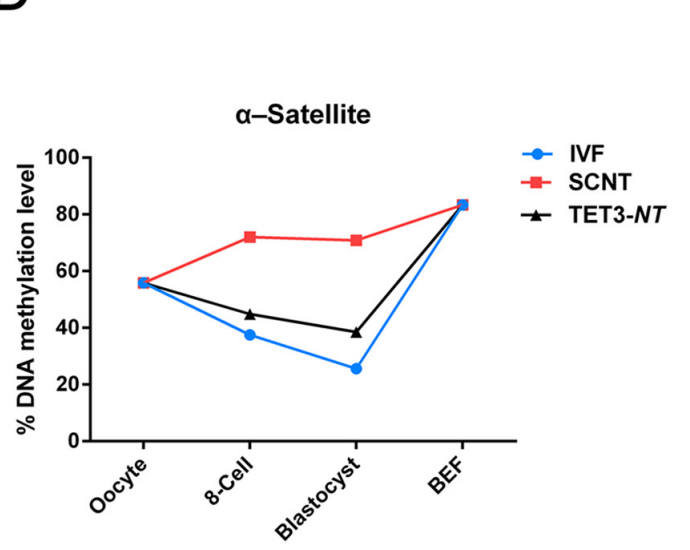

$B$
C

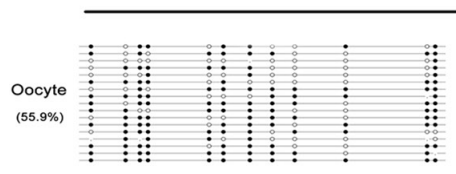

a-satellite

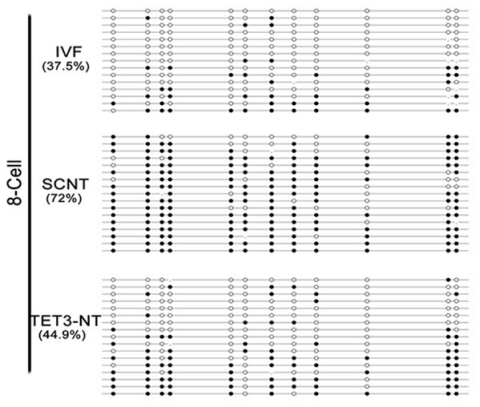

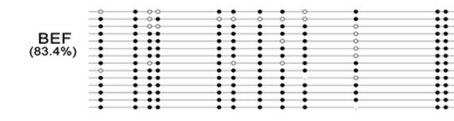

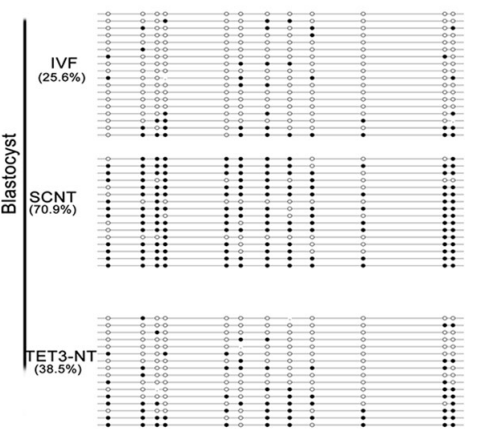

Figure 4 Dynamic DNA methylation profiles of satellite I and $\alpha$-satellite in oocyte- to blastocyst IVF, SCNT, TET3-NT embryos and BEFs. (A and B) DNA methylation status of satellite I measured using bisulfite sequencing in oocytes as well as IVF, SCNT, and TET3-NT embryos and BEFs. (C and D) DNA methylation status of $\alpha$-satellite measured using bisulfite sequencing in oocytes as well as IVF, SCNT, and TET3-NT embryos and BEFs. The filled (black) circles correspond to methylated cytosines, the unfilled (white) circles indicate unmethylated cytosines, and the small vertical lines without a circle correspond to missing values.

(57.5\%) stages, and ICR DNA methylation levels were significantly lower in bovine SCNT 8-cell embryos $(59.7 \%)$ and blastocysts $(38.7 \%)$ than was observed in IVF embryos $(62.5 \pm 7.5 \%)$ (Fig. 7B). As expected for the H19-IGF2 ICR, the analyzed region was highly methylated in BEFs (81.8\%) but hypomethylated in oocytes $(4.5 \%)$. In contrast, moderate DNA methylation was maintained in bovine IVF 8 -cell embryos (46.2\%) and blastocysts (57.5\%), and the ICR DNA methylation level was significantly decreased in bovine SCNT
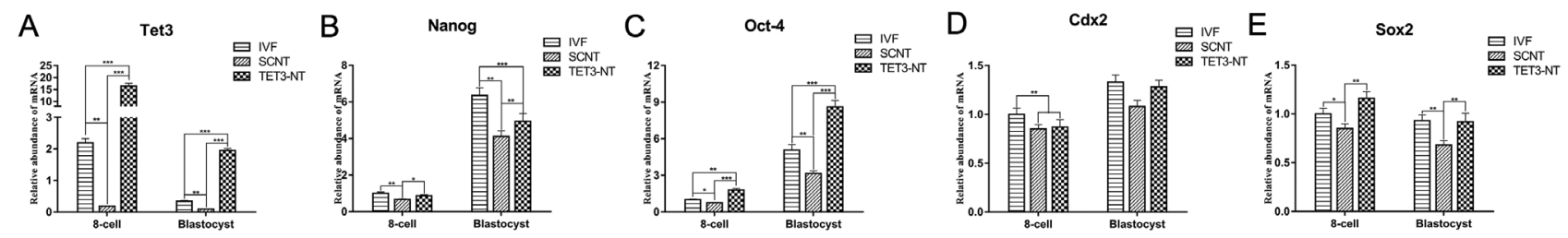

Figure 5 TET3 overexpression improves the relative expression of pluripotency genes. Relative expression level of TET3 (A) and the pluripotency genes Nanog (B) and Oct-4 (C), Cdx2 (D) and Sox2 (E) in bovine SCNT embryos. The gene expression levels in the IVF 8-cell stage were used to calibrate the sample (expression set to 1 ). The data are presented as the mean \pm S.E.M. ${ }^{* *} P<0.01,{ }^{* * *} P<0.001$. 
A

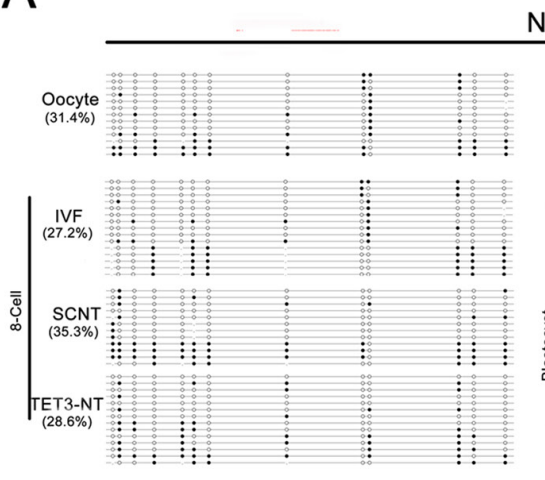

Nanog

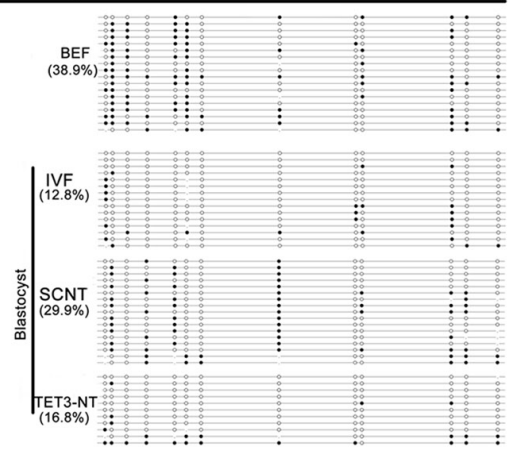

C
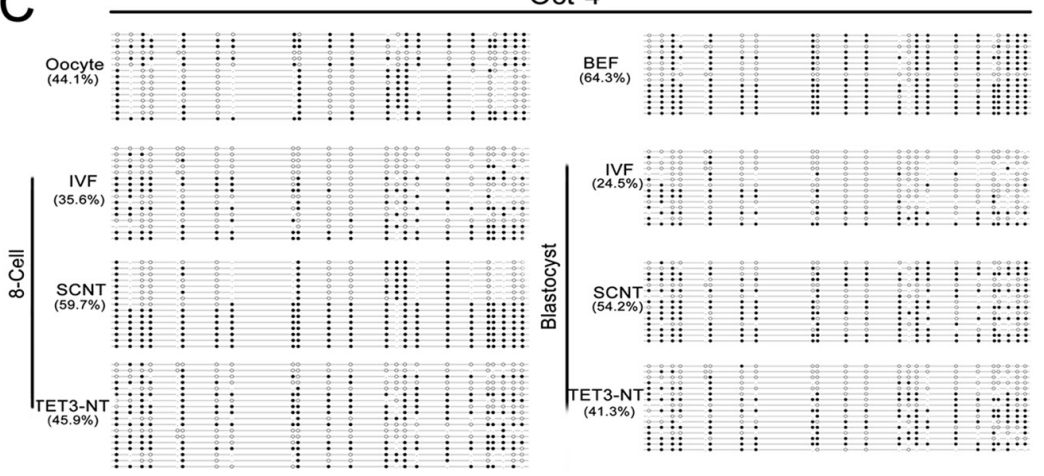

B
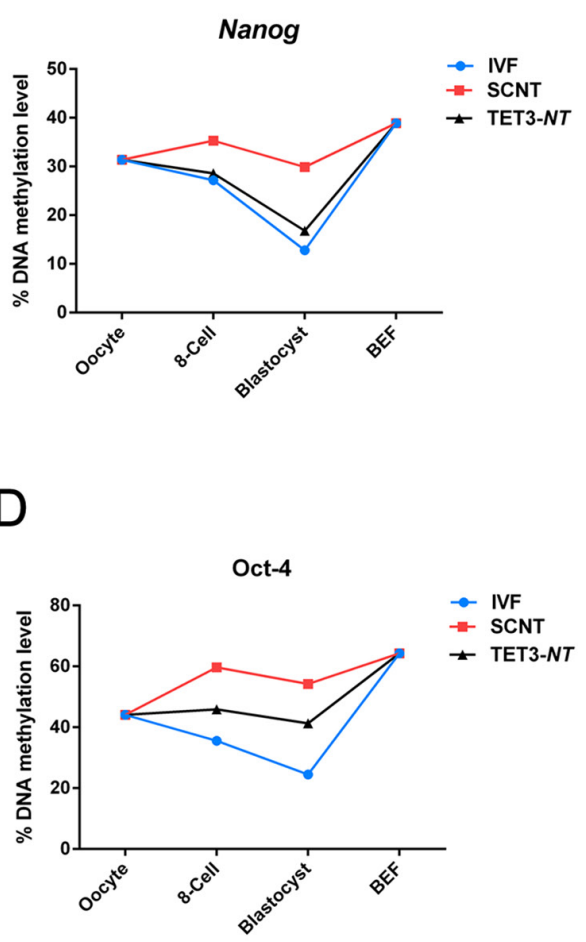

Figure 6 Dynamic DNA methylation profiles of pluripotency genes Nanog and Oct-4 in oocyte- to blastocyst IVF, SCNT, TET3-NT embryos and BEF. (A and B) DNA methylation status of Nanog measured using bisulfite sequencing in oocytes as well as IVF, SCNT, and TET3-NT embryos and BEFs. (C and D) DNA methylation status of Oct-4 measured using bisulfite sequencing in oocytes as well as IVF, SCNT, and TET3-NT embryos and BEFs. The filled (black) circles correspond to methylated cytosines, the unfilled (white) circles indicate unmethylated cytosines and the small vertical lines without a circle correspond to missing values.

blastocysts $(38.7 \%)$ compared to that observed in IVF blastocytes (Fig. 7B). However, no difference in DNA methylation profile was observed in TET3-NT embryos compared to the WT SCNT embryos, which showed $56.4 \%$ DNA methylation at the 8-cell stage and 30.6\% DNA methylation at the blastocyst stages, respectively (Fig. 7B). Furthermore, H19 and IGF2 mRNA levels were detected in the IVF and NT 8-cell embryos and blastocysts. H19 showed much higher expression in IVF blastocyst embryos, whereas the expression of IGF2 was lower in bovine IVF embryos than that observed in SCNT embryos. In addition, expression of the H19 and IGF2 genes did not differ significantly between WT SCNT and TET3-NT embryos (Fig. 7D and E).

\section{Effects of TET3 expression on cell apoptosis in bovine SCNT embryos}

The expression of key genes related to apoptosis was assessed in the embryos using real-time PCR and the TUNEL assays (Fig. 8A). Apoptotic staining results showed that the percentage of apoptotic cells in the TET3-NT blastocysts was significantly lower than that observed in WT SCNT blastocysts but not significantly different from that detected in IVF blastocysts (Fig. 8B). The transcriptional levels of the apoptotic genes $\mathrm{BCl}-2$ and Bax were analyzed by RT-qPCR and were observed to be unchanged in embryos at the 8-cell stage. In addition, the expression of Bax in TET3-NT embryos was significantly decreased, while $\mathrm{BCl}-2$ expression was higher in TET3-NT embryos than that detected in WT NT embryos at the blastocyst stage (Fig. 8C and D).

\section{Discussion}

Animal cloning using the SCNT technique has been applied to animal model construction, species conservation, and xenotransplantation. However, SCNT efficiency is still low in essentially all species (Campbell et al. 2007). This finding has been speculated to be related to incomplete epigenetic reprogramming during the process of SCNT (Matoba \& Zhang 2018). Therefore, successful SCNT reprogramming should include the reprogramming of histone modification and DNA methylation profiles from the donor cell to zygotes. In previous studies, high levels of H3K9 methylation were reported to inhibit the activation of genes in two-cell embryos, and the removal of $\mathrm{H} 3 \mathrm{~K} 9 \mathrm{me} 3$ was shown to 
A

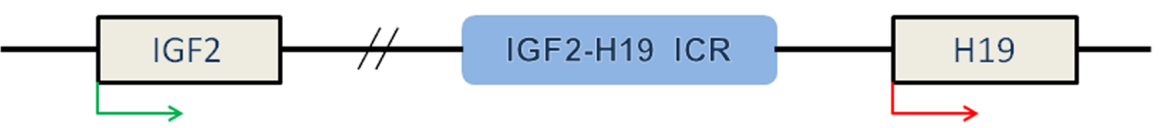

$\mathrm{H} 19$

B

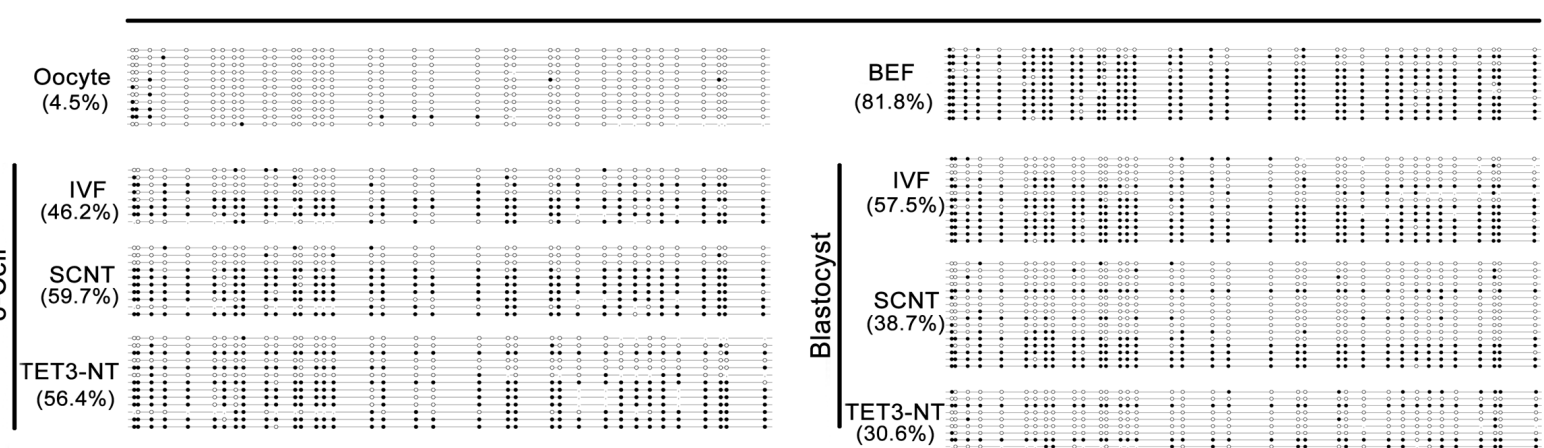

C

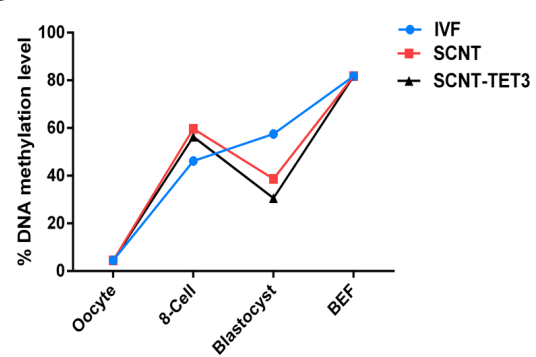

D

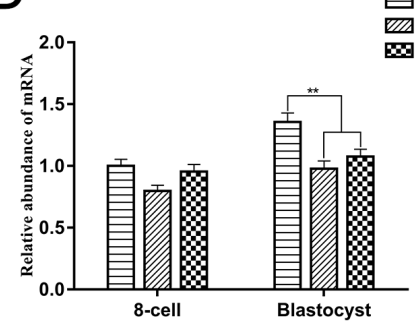

IGF2

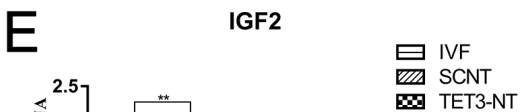

Figure 7 Methylation profiles and relative expression of the identified bovine intergenic /GF2-H19 ICR. (A) Schematic drawing of the bovine IGF2-H19 region. (B and C) DNA methylation status of IGF2-H19 ICR measured using bisulfite sequencing in oocytes as well as IVF, SCNT, and TET3-NT embryos and BEFs. (D and E) The mRNA expression levels of imprinted genes H19 and IGF2 at the 8-cell and blastocyst stages. The gene expression levels in the IVF 8-cell stage were used to calibrate the sample (expression set to 1). The data are presented as the mean \pm S.E.M. ${ }^{* *} P<0.01,{ }^{* * *} P<0.001$

A

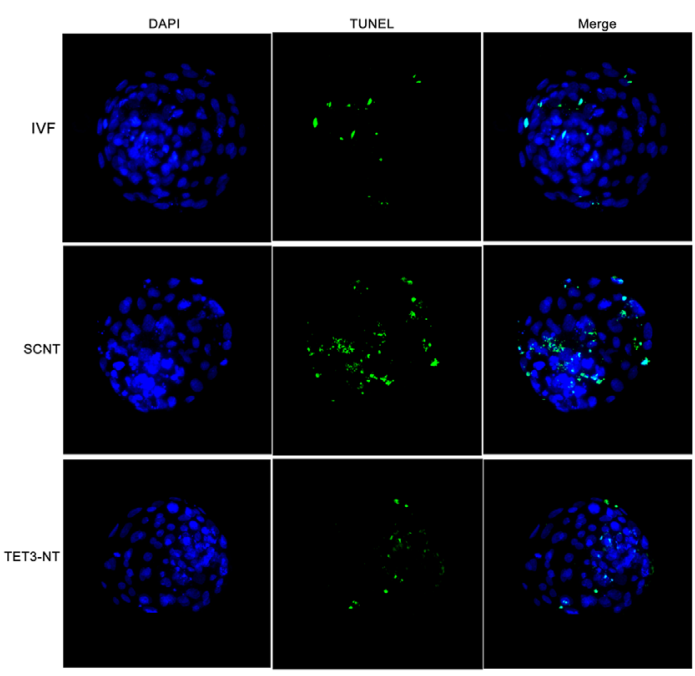

B

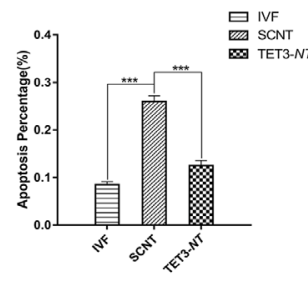

C
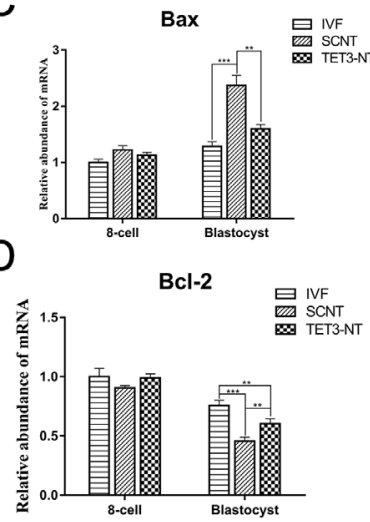

Figure 8 Effect of TET3 overexpression in bovine SCNT embryos on apoptosis. (A) Apoptotic cells (green) in the nuclei (blue) of blastocysts developed from IVF, SCNT and TET3-NT embryos. (B) Percentage of apoptotic cells in blastocysts per treatment group. (C and D) RT-qPCR analysis of the apoptotic related genes $\mathrm{Bax}$ and $\mathrm{BCl}-2$ at the 8-cell and blastocyst stages for the IVF, SCNT and TET3-NT embryos. The expression levels of 8-cell embryos in the IVF group were used for sample normalization (expression set to 1 ). The data are presented as the mean \pm S.E.M. from three independent experiments; ${ }^{*} P<$ $0.05, * * P<0.01$. Scale bar $=50 \mu \mathrm{m}$. 
substantially improve the transcriptional reprogramming of cloned embryos (Liu et al. 2016). In addition, H3K4 methylation was confirmed to be a barrier for SCNT embryo arrest, and reduced H3K4 methylation could markedly improve cloning efficiency (Zhang et al. 2018). In mammals, DNA methylation at $5 \mathrm{mC}$ is another important epigenetic modification that plays a key role in normal embryonic development (Gao et al. 2018). DNA methylation is mediated and maintained by DNA methyltransferases (DNMTS) but can be removed by TET protein-mediated oxidation (Gu et al. 2011). In mice, DNA is extensively demethylated by the TET3 protein during preimplantation embryo development through a combination of active and passive processes (Shen et al. 2014). Research in pigs has shown that TET1 is involved in DNA demethylation during early embryonic development (Cao et al. 2014). Our recent studies revealed that TET3 expression was higher than that of TET1 and TET2 in bovine embryos. Inhibition or knockdown of TET3 in embryos significantly increased the level of DNA methylation, suggesting that TET3 is primarily responsible for active DNA demethylation in bovine early embryonic development (Zhang et al. 2017, Cheng et al. 2019). After determining that TET3 is a key factor that mediates active DNA demethylation in mammalian embryos, several studies have shown that TET3 stored in oocytes can be localized to the PPN in mouse SCNT embryos and induce the transformation of $5 \mathrm{mC}$ into $5 \mathrm{hmC}$, suggesting that active DNA demethylation does occur in SCNT embryos (Iqbal et al. 2011, Wossidlo et al. 2011). In this study, we demonstrated that, similar to mice, DNA methylation in the somatic cell genome acts as a barrier for bovine SCNT reprogramming. Elimination of DNA methylation by overexpression of the DNA demethylase TET3 facilitated epigenetic reprogramming, thereby allowing bovine SCNT embryos to develop more efficiently. Our study thus found that TET3 is an intrinsic defective regulator that contributes to the unsuccessful removal of DNA methylation in bovine SCNT embryos and that TET3 is crucial for this reprogramming process (Fig. 9).

It has been well shown that TET3 promotes epigenomic or pluripotent genome changes in mammals (Gao et al. 2013). Indeed, we observed increased expression of the pluripotency genes Nanog, Sox2, and Oct-4 after fluorescent quantitation, the promoter regions of which can be demethylated by the TET protein. Interestingly, expression levels of the methyltransferase DNMT1 in the TET3-overexpression group were higher than those observed in the negative control and untreated groups, revealing an intricate interplay between TET3driven DNA demethylation and de novo methylation (Amouroux et al. 2016). In addition, our results suggest that overexpression of TET3 in bovine fibroblasts did not change the transcriptional expression levels of DNA methyltransferases (DNMT3a/3b), lysine-specific demethylases (KDM3a/4a/4c/5b) or imprinted genes (H19 and IGF2), suggesting that the catalytic capacity of TET3 is selective and that not all genes are demethylated by TET3.

In previous studies, the nuclei of donor cumulus cells were first injected into the enucleated oocytes using a micromanipulator. Then, these SCNT embryos were microinjected with target mRNA after activation (Chung et al. 2015, Liu et al. 2018). The advantage of this approach is that it does not require screening for positive clones, simplifying the process, but it also raises some questions. First, injecting SCNT embryos after nuclear transplantation will cause further damage to oocytes and affect later embryonic development. More importantly, after direct injection of overexpressed mRNA, the mRNA requires some time for expression. Furthermore, with respect to the proteins responsible for reprogramming somatic cells, only those stored by the oocyte are available, indicating that somatic gene expression from the donor genome may not be immediately regulated by ooplasma. Thus, we conducted somatic nuclear

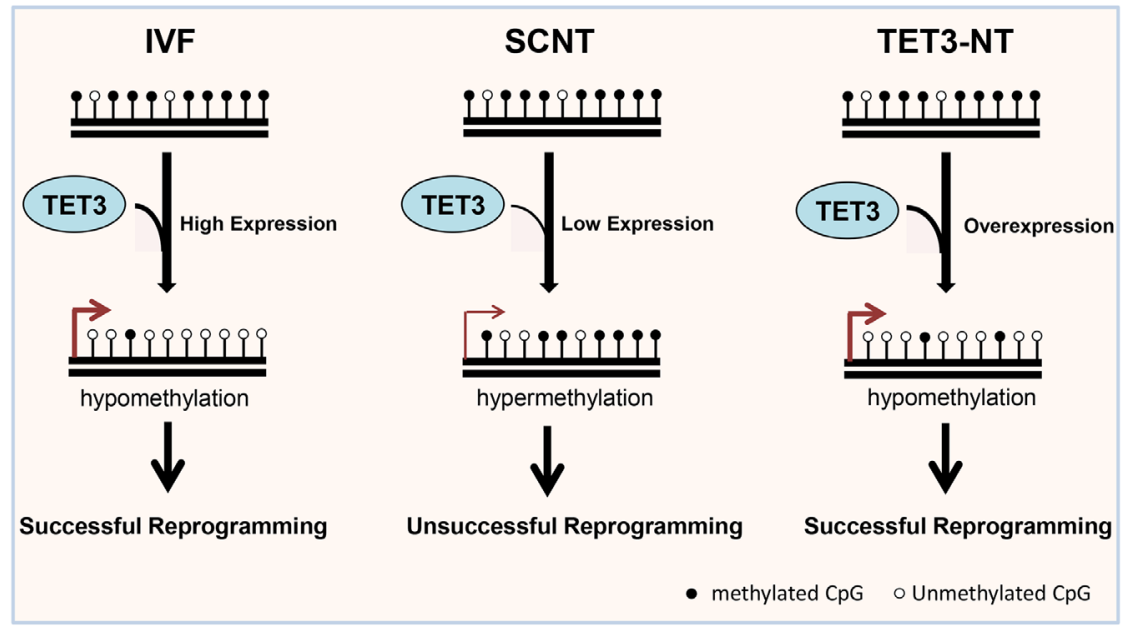

Figure 9 TET3 is an epigenetic regulator during embryo development. Schematic representation of the proposed model illustrating the reason for the associated DNA demethylation in IVF embryos and $5 \mathrm{mC}$ aberrancies in SCNT embryos. Overexpression of TET3 can remove the $5 \mathrm{mC}$ barriers and lead to successful nuclear reprogramming in bovine SCNT embryos. 
transfer using bovine fibroblasts overexpressing TET3. The results indicated that the TET3-GFP fusion protein was stably expressed during zygote division. Combined with TET3 and FLAG immunofluorescence staining, the results showed that the TET3 protein was stably and highly expressed in embryos at different stages. Previous research has shown that genome-wide DNA methylation reprogramming is a dynamic balance between strong focused remethylation through DNMTs and drastic global demethylation by TET proteins during preimplantation development (Zhu et al. 2018). The latest studies have reported that inhibition of DNMTs specifically enhances SCNT efficiency in mice (Gao et al. 2018). In this study, TET3 overexpression in bovine somatic cells before SCNT rescued these demethylation defects and significantly improved the developing rate of cloned embryo, with the blastocyst rate significantly increasing from 12.1 to $29.9 \%$. We also analyzed the DNA methylation levels of satellite $I$ and $\alpha$-satellite, representative repeat elements that overlap the majority of the genome, using sodium bisulfite genomic sequencing (BSP). Our results showed that the DNA methylation levels of satellite I and $\alpha$-satellite in SCNT embryos were more similar to those of fibroblast cells than of IVF embryos, indicating that global DNA methylation reprogramming in bovine SCNT embryos had not yet been completed during the development of the embryo before implantation. Unlike the dynamic global DNA methylation patterns observed in cows, DNA hypermethylation levels similar to those in fibroblasts were maintained until the 4-cell stage in mouse cloned embryos (Liu et al. 2016).

Previous studies have demonstrated that the expression of pluripotency genes plays an essential role in preimplantation embryonic development and that the activation of pluripotency genes can improve reprogramming efficiency (Gomez et al. 2012). Overexpression of pluripotency transcription factors, such as Nanog and Oct4, in donor cells also increased the efficiency of SCNT embryos to some extent (Zhang et al. 2011, Goissis et al. 2013). In our experiments, Nanog, Oct-4 and Sox2 mRNA transcription was significantly higher in TET3-NT embryos than in SCNT embryos at the 8-cell and blastocyst stages. We subsequently examined the DNA methylation status at the promoters of the pluripotency genes Nanog and Oct-4 in IVF embryos, SCNT embryos, and TET3-NT embryos. The results showed that promoter regions of the Nanog and Oct-4 loci in TET3-NT embryos were more hypermethylated, similar to IVF embryos, than those in SCNT embryos at the 8-cell and blastocyst stages, indicating that TET3 overexpression significantly decreased DNA methylation in the Oct-4 and Nanog promoter regions and then reactivated pluripotency genes, contributing to an increased SCNT embryo developmental capacity.
Numerous studies have reported deficient epigenetic reprogramming with abnormal imprinted gene expression in SCNT embryos (Young et al. 2001, Perecin et al. 2009, Suzuki et al. 2009). In this study, we analyzed the methylation and transcription levels in the ICR region of the typical imprinted genes H19/IGF2. The H19/IGF2 ICR was hypermethylated in bovine fibroblast cells and hypomethylated in oocytes. However, the H19/IGF2 ICR in SCNT embryos exhibited lower methylation levels than that those observed in IVF embryos at the 8-cell and blastocyst stages. Similar to our previous studies, these results showed that overexpression of TET3 did not change the level of DNA methylation or expression of the imprinted genes $\mathrm{H} 19$ and IGF2 in TET3-NT embryos, indicating that the imprinted genes H19 and IGF2 ICR resisted demethylation by the TET3 protein in bovine SCNT embryos (Zhang et al. 2017). These results showed that DNA methylation of the imprinted genes H19-IGF2 ICR remains unaffected by this wave of reprogramming in SCNT embryos and maintains parentspecific activity for further development. In addition, we observed that TET3-NT blastocysts possessed more total cells and fewer apoptotic cells than the SCNT blastocysts, similar to IVF embryos, and no difference in apoptotic cell numbers in 8-cell stage embryos was observed between these three groups.

Furthermore, we observed that the transcription levels of the pro-apoptotic gene Bax were significantly lower, in TET3-NT embryos at the blastocyst stage than in SCNT embryos, while those of the anti-apoptotic gene $B C l-2$ were higher. These effects may be due to TET3 overexpression partially preventing the occurrence of apoptosis by promoting anti-apoptotic gene expression and inhibiting that of pro-apoptotic genes.

In summary, the results of our study reveal that aberrant DNA methylation reprogramming is a major epigenetic modification obstruction to the developmental potential of cloned embryos. Overexpression of TET3 in donor cells could decrease the DNA methylation level and facilitate the activation of pluripotency genes in bovine cloned embryos, thereby improving the efficiency of bovine SCNT embryos. These findings may ultimately be used in promoting application of the large-animal cloning technique.

\section{Supplementary materials}

This is linked to the online version of the paper at https://doi. org/10.1530/REP-20-0021.

\section{Declaration of interest}

The authors declare that there is no conflict of interest that could be perceived as prejudicing the impartiality of the research reported. 


\section{Funding}

This work was supported by the National Nature Science Foundation of China (No. 31472093), the National Nature Science Foundation of China (No. 31872434), the National Key R\&D Program of China (grant number 2017YFA0104400), and the Program for Changjiang Scholars and Innovative Research Team in University (grant number IRT_16R32).

\section{Author contribution statement}

B T, X Z and Z L conceived and designed the experiments. J $\mathrm{Z}$ and $\mathrm{L} \mathrm{H}$ performed the experiments and analyzed the data. All the authors contributed to interpretation of the results throughout the study and approved the final version of the manuscript.

\section{References}

Aflalo ED, Sod-Moriah UA, Potashnik G \& Har-Vardi I 2005 Expression of plasminogen activators in preimplantation rat embryos developed in vivo and in vitro. Reproductive Biology and Endocrinology 3 7. (https:// doi.org/10.1186/1477-7827-3-7)

Amouroux R, Nashun B, Shirane K, Nakagawa S, Hill PW, D'Souza Z, Nakayama M, Matsuda M, Turp A, Ndjetehe E et al. 2016 De novo DNA methylation drives $5 \mathrm{hmC}$ accumulation in mouse zygotes. Nature Cell Biology 18 225-233. (https://doi.org/10.1038/ncb3296)

Andrabi SM \& Maxwell WM 2007 A review on reproductive biotechnologies for conservation of endangered mammalian species. Animal Reproduction Science 99 223-243. (https://doi.org/10.1016/j. anireprosci.2006.07.002)

Armstrong L, Lako M, Dean W \& Stojkovic M 2006 Epigenetic modification is central to genome reprogramming in somatic cell nuclear transfer. Stem Cells 24 805-814. (https://doi.org/10.1634/stemcells.2005-0350)

Bock C, Reither S, Mikeska T, Paulsen M, Walter J \& Lengauer T 2005 BiQ Analyzer: visualization and quality control for DNA methylation data from bisulfite sequencing. Bioinformatics 21 4067-4068. (https:// doi.org/10.1093/bioinformatics/bti652)

Campbell KH, Fisher P, Chen WC, Choi I, Kelly RD, Lee JH \& Xhu J 2007 Somatic cell nuclear transfer: past, present and future perspectives. Theriogenology 68 (Supplement 1) S214-S231. (https://doi.org/10.1016/j. theriogenology.2007.05.059)

Cao Z, Zhou N, Zhang Y, Zhang Y, Wu R, Li Y, Zhang Y \& Li N 2014 Dynamic reprogramming of 5-hydroxymethylcytosine during early porcine embryogenesis. Theriogenology 81 496-508. (https://doi. org/10.1016/j.theriogenology.2013.10.025)

Cheng H, Zhang J, Zhang S, Zhai YH, Jiang Y, An XL, Ma XL, Zhang XM, Li ZY \& Tang B 2019 Tet3 is required for normal in vitro fertilization preimplantation embryos development of bovine. Molecular Reproduction and Development 86 298-307. (https://doi.org/10.1002/ mrd.23105)

Chung YG, Matoba S, Liu Y, Eum JH, Lu F, Jiang W, Lee JE, Sepilian V, Cha KY, Lee DR et al. 2015 Histone demethylase expression enhances human somatic cell nuclear transfer efficiency and promotes derivation of pluripotent stem cells. Cell Stem Cell 17 758-766. (https://doi. org/10.1016/j.stem.2015.10.001)

Dean W, Santos F, Stojkovic M, Zakhartchenko V, Walter J, Wolf E \& Reik W 2001 Conservation of methylation reprogramming in mammalian development: aberrant reprogramming in cloned embryos. PNAS 98 13734-13738. (https://doi.org/10.1073/pnas.241522698)

Enright BP, Sung LY, Chang CC, Yang X \& Tian XC 2005 Methylation and acetylation characteristics of cloned bovine embryos from donor cells treated with 5-aza-2'-deoxycytidine. Biology of Reproduction 72 944-948. (https://doi.org/10.1095/biolreprod.104.033225)

Gao Y, Chen J, Li K, Wu T, Huang B, Liu W, Kou X, Zhang Y, Huang H, Jiang Y et al. 2013 Replacement of Oct4 by Tet1 during iPSC induction reveals an important role of DNA methylation and hydroxymethylation in reprogramming. Cell Stem Cell 12 453-469. (https://doi.org/10.1016/j. stem.2013.02.005)

Gao R, Wang C, Gao Y, Xiu W, Chen J, Kou X, Zhao Y, Liao Y, Bai D, Qiao Z et al. 2018 Inhibition of aberrant DNA Re-methylation improves post-implantation development of somatic cell nuclear transfer embryos. Cell Stem Cell 23 426.e5-435.e5. (https://doi.org/10.1016/j. stem.2018.07.017)

Goissis MD, Suhr ST \& Cibelli JB 2013 Effects of donor fibroblasts expressing OCT4 on bovine embryos generated by somatic cell nuclear transfer. Cell Reprogram 15 24-34. (https://doi.org/10.1089/cell.2012.0055)

Gomez MC, Biancardi MN, Jenkins JA, Dumas C, Galiguis J, Wang G \& Earle Pope C 2012 Scriptaid and 5-aza-2'deoxycytidine enhanced expression of pluripotent genes and in vitro developmental competence in interspecies black-footed cat cloned embryos. Reproduction in Domestic Animals 47 (Supplement 6) 130-135. (https://doi.org/10.1111/ rda.12027)

Gu TP, Guo F, Yang H, Wu HP, Xu GF, Liu W, Xie ZG, Shi L, He X, Jin SG et al. 2011 The role of Tet3 DNA dioxygenase in epigenetic reprogramming by oocytes. Nature 477 606-610. (https://doi.org/10.1038/nature10443)

Gurdon JB 1962 The developmental capacity of nuclei taken from intestinal epithelium cells of feeding tadpoles. Journal of Embryology and Experimental Morphology 10 622-640.

He YF, Li BZ, Li Z, Liu P, Wang Y, Tang Q, Ding J, Jia Y, Chen Z, Li L et al. 2011 Tet-mediated formation of 5-carboxylcytosine and its excision by TDG in mammalian DNA. Science 333 1303-1307. (https://doi. org/10.1126/science.1210944)

Hormanseder E, Simeone A, Allen GE, Bradshaw CR, Figlmuller M, Gurdon J \& Jullien J 2017 H3K4 methylation-dependent memory of somatic cell identity inhibits reprogramming and development of nuclear transfer embryos. Cell Stem Cell 21 135.e6-143.e6. (https://doi. org/10.1016/j.stem.2017.03.003)

Iqbal K, Jin SG, Pfeifer GP \& Szabo PE 2011 Reprogramming of the paternal genome upon fertilization involves genome-wide oxidation of 5-methylcytosine. PNAS 108 3642-3647. (https://doi.org/10.1073/ pnas.1014033108)

Liu W, Liu X, Wang C, Gao Y, Gao R, Kou X, Zhao Y, Li J, Wu Y, Xiu W et al. 2016 Identification of key factors conquering developmental arrest of somatic cell cloned embryos by combining embryo biopsy and singlecell sequencing. Cell Discovery 2 16010. (https://doi.org/10.1038/ celldisc.2016.10)

Liu X, Wang Y, Gao Y, Su J, Zhang J, Xing X, Zhou C, Yao K, An Q \& Zhang Y 2018 H3K9 demethylase KDM4E is an epigenetic regulator for bovine embryonic development and a defective factor for nuclear reprogramming. Development 145 dev158261. (https://doi.org/10.1242/ dev.158261)

Livak KJ \& Schmittgen TD 2001 Analysis of relative gene expression data using real-time quantitative PCR and the 2(T)(-Delta Delta C) method. Methods 25 402-408. (https://doi.org/10.1006/meth.2001.1262)

Lu F, Liu Y, Jiang L, Yamaguchi S \& Zhang Y 2014 Role of Tet proteins in enhancer activity and telomere elongation. Genes and Development 28 2103-2119. (https://doi.org/10.1101/gad.248005.114)

Matoba S \& Zhang Y 2018 Somatic cell nuclear transfer reprogramming: mechanisms and applications. Cell Stem Cell 23 471-485. (https://doi. org/10.1016/j.stem.2018.06.018)

Okae H, Matoba S, Nagashima T, Mizutani E, Inoue K, Ogonuki N, Chiba H, Funayama R, Tanaka S, Yaegashi N et al. 2014 RNA sequencing-based identification of aberrant imprinting in cloned mice. Human Molecular Genetics 23 992-1001. (https://doi.org/10.1093/hmg/ddt495)

Peat JR \& Reik W 2012 Incomplete methylation reprogramming in SCNT embryos. Nature Genetics 44 965-966. (https://doi.org/10.1038/ ng.2393)

Perecin F, Meo SC, Yamazaki W, Ferreira CR, Merighe GK, Meirelles FV \& Garcia JM 2009 Imprinted gene expression in in vivo- and in vitroproduced bovine embryos and chorio-allantoic membranes. Genetics and Molecular Research 8 76-85. (https://doi.org/10.4238/vol8-1gmr541)

Santos F, Zakhartchenko V, Stojkovic M, Peters A, Jenuwein T, Wolf E, Reik W \& Dean W 2003 Epigenetic marking correlates with developmental potential in cloned bovine preimplantation embryos. Current Biology 13 1116-1121. (https://doi.org/10.1016/s09609822(03)00419-6)

Shen L, Inoue A, He J, Liu YT, Lu FL \& Zhang Y 2014 Tet3 and DNA replication mediate demethylation of both the maternal and paternal 
genomes in mouse zygotes. Cell Stem Cell 15 459-471. (https://doi. org/10.1016/j.stem.2014.09.002)

Stelzer Y, Wu H, Song Y, Shivalila CS, Markoulaki S \& Jaenisch R 2016 Parent-of-origin DNA methylation dynamics during mouse development. Cell Reports 16 3167-3180. (https://doi.org/10.1016/j. celrep.2016.08.066)

Suzuki J, Therrien J, Filion F, Lefebvre R, Goff AK \& Smith LC 2009 In vitro culture and somatic cell nuclear transfer affect imprinting of SNRPN gene in pre- and post-implantation stages of development in cattle. $B M C$ Developmental Biology 9 9. (https://doi.org/10.1186/1471-213X-9-9)

Van Thuan N, Bui HT, Kim JH, Hikichi T, Wakayama S, Kishigami S, Mizutani E \& Wakayama T 2009 The histone deacetylase inhibitor scriptaid enhances nascent mRNA production and rescues full-term development in cloned inbred mice. Reproduction 138 309-317. (https://doi.org/10.1530/REP-08-0299)

Wang F, Kou Z, Zhang Y \& Gao S 2007 Dynamic reprogramming of histone acetylation and methylation in the first cell cycle of cloned mouse embryos. Biology of Reproduction 77 1007-1016. (https://doi. org/10.1095/biolreprod.107.063149)

Wang Z, Zhao T, Zhang P, Zhang S, Guan J, Ma X, Yin Y, Zhang J, Tang B \& Li Z 2011 Histone deacetylase 1 down-regulation on developmental capability and histone acetylation in bovine oocytes and parthenogenetic embryos. Reproduction in Domestic Animals 46 1022-1028. (https://doi. org/10.1111/j.1439-0531.2011.01778.x)

Wei YC, Huan YJ, Shi YQ, Liu ZF, Bou G, Luo YB, Zhang L, Yang CR, Kong QR, Tian JT et al. 2011 Unfaithful maintenance of methylation imprints due to loss of maternal nuclear Dnmt1 during somatic cell nuclear transfer. PLOS ONE 6 e20154. (https://doi.org/10.1371/journal. pone.0020154)

Wilmut I, Schnieke AE, McWhir J, Kind AJ \& Campbell KH 1997 Viable offspring derived from fetal and adult mammalian cells. Nature 385 810-813. (https://doi.org/10.1038/385810a0)

Wossidlo M, Nakamura T, Lepikhov K, Marques CJ, Zakhartchenko V, Boiani M, Arand J, Nakano T, Reik W \& Walter J 2011 5 -Hydroxymethylcytosine in the mammalian zygote is linked with epigenetic reprogramming. Nature Communications 2 241. (https://doi. org/10.1038/ncomms1240)
Yang X, Smith SL, Tian XC, Lewin HA, Renard JP \& Wakayama T 2007 Nuclear reprogramming of cloned embryos and its implications for therapeutic cloning. Nature Genetics 39 295-302. (https://doi. org/10.1038/ng1973)

Young LE, Fernandes K, McEvoy TG, Butterwith SC, Gutierrez CG, Carolan C, Broadbent PJ, Robinson JJ, Wilmut I \& Sinclair KD 2001 Epigenetic change in IGF2R is associated with fetal overgrowth after sheep embryo culture. Nature Genetics 27 153-154. (https://doi. org/10.1038/84769)

Zhang L, Luo YB, Bou G, Kong QR, Huan YJ, Zhu J, Wang JY, Li H, Wang F, Shi YQ et al. 2011 Overexpression Nanog activates pluripotent genes in porcine fetal fibroblasts and nuclear transfer embryos. Anatomical Record 294 1809-1817. (https://doi.org/10.1002/ar.21457)

Zhang S, Chen X, Wang F, An X, Tang B, Zhang X, Sun L \& Li Z 2016 Aberrant DNA methylation reprogramming in bovine SCNT preimplantation embryos. Scientific Reports 6 30345. (https://doi.org/10.1038/srep30345)

Zhang J, Zhang S, Wang Y, Cheng H, Hao L, Zhai Y, Zhang Z, An X, Ma X, Zhang X et al. 2017 Effect of TET inhibitor on bovine parthenogenetic embryo development. PLoS ONE 12 e0189542. (https://doi.org/10.1371/ journal.pone.0189542)

Zhang Z, Zhai Y, Ma X, Zhang S, An X, Yu H \& Li Z 2018 Down-regulation of H3K4me3 by MM-102 facilitates epigenetic reprogramming of porcine somatic cell nuclear transfer embryos. Cellular Physiology and Biochemistry 45 1529-1540. (https://doi.org/10.1159/000487579)

Zhu P, Guo H, Ren Y, Hou Y, Dong J, Li R, Lian Y, Fan X, Hu B, Gao Y et al. 2018 Single-cell DNA methylome sequencing of human preimplantation embryos. Nature Genetics 50 12-19. (https://doi.org/10.1038/s41588017-0007-6)

Received 15 January 2020

First decision 9 March 2020

Revised manuscript received 8 June 2020

Accepted 15 June 2020 